\title{
Bottom-up effects of streambed drying on consumer performance through changes in resource quality
}

\author{
Esther Mas-Martí $^{1} \cdot$ Isis Sanpera-Calbet $^{1} \cdot$ Isabel Muñoz $^{1}$
}

Received: 28 September 2016 / Accepted: 28 March 2017 / Published online: 1 April 2017

(C) The Author(s) 2017. This article is an open access publication

\begin{abstract}
Stream flow intermittency and subsequent streambed drying, which already occurs in most biomes worldwide, is expected to increase in many regions due to both climate change and increased water demand. We studied the effects of streambed drying on leaves and epilithic biofilm and their effects on potential consumers. In the field, resources were conditioned according to the following treatments: (i) continuously submerged (PERM), (ii) submerged, exposed to the dry streambed and then submerged again (INT), or (iii) conditioned in the dry streambed and only allowed instream conditioning for 1 week (DRY, only for leaves). The results showed that drying affects resource quality, and the effects on biofilm were more severe than those on leaves. Both DRY leaves and INT biofilm showed lower microbial colonization and nitrogen accrual, whereas INT leaves had similar characteristics to PERM leaves. Drying resulted in decreased shredder and herbivore consumption rates and detritivore growth. Our results suggest that bottom-up effects of drying through changes in resource quality can constrain detritivore growth in temporary streams, potentially affecting stream secondary production and invertebrate-mediated organic matter cycling under a drier climate scenario.
\end{abstract}

Electronic supplementary material The online version of this article (doi:10.1007/s00027-017-0531-6) contains supplementary material, which is available to authorized users.

\footnotetext{
Isabel Muñoz

imunoz@ub.edu

1 Department of Evolutionary Biology, Ecology and Environmental Sciences, Universitat de Barcelona, Av. Diagonal, 643, 08028 Barcelona, Spain
}

Keywords Temporary rivers · Consumption rate . Growth rate $\cdot$ Stoichiometry $\cdot$ Herbivore $\cdot$ Detritivore

\section{Introduction}

Temporary streams, which exhibit periodical flow interruption, are present in most biomes worldwide (Larned et al. 2010). The expected decline in precipitation and higher evapotranspiration rates resulting from increased air temperature will increase drought and likely reduce stream runoff in many regions, including the Mediterranean basin (IPCC 2007) and have already been observed in small catchments in eastern and southern Europe (Stahl et al. 2010). These climatic effects will be reinforced by increased water demand due to population growth and increased urbanization and irrigated agriculture (Arnell 1999; Sabater and Tockner 2010). Furthermore, due to frequent temporal and spatial mismatch between water demand and its availability (Bonada and Resh 2013), the occurrence, frequency and duration of flow intermittency are expected to increase. In small- and middle-sized streams, this will likely result in the drying of many permanent habitats while intermittent reaches might dry out completely.

After flow disruption, changes in nutrient concentrations and temperature, and reductions in dissolved oxygen levels and water velocity, constrain habitat suitability for many species (Boulton 2003; Dewson and Russell 2007). Moreover, effects can be exacerbated if the streambed dries out completely, causing local extinctions of species that are unable to survive and recover from drought (Lytle and Poff 2004). Besides these direct effects on stream biota, indirect effects of drying might also arise after flow recovery through changes in resource quantity and quality. Hydric 
stress can cause earlier leaf abscission from riparian forests (Sanpera-Calbet et al. 2016), altering food availability to autumnal shredders in temporary streams. Stream drying also negatively affects aquatic microbial communities that colonise leaves or develop in biofilms (Bruder et al. 2011; Romaní et al. 2013). Although algae and bacteria seem to recover rapidly after flow resumption (Romaní et al. 2013), effects on fungal biomass vary according to drying intensity and duration (Langhans and Tockner 2006; Bruder et al. 2011). Because conditioning by these microorganisms influences the chemical composition of resources (Graça 2001; Ylla et al. 2010; Timoner et al. 2012), one might expect differences in the quality of resources available to consumers. Indeed, a decrease in the polysaccharide, amino acid and lipid content of benthic resources has been observed in an intermittent stream upon rewetting (Ylla et al. 2010) while greater periods of flow intermittence increased C:N ratios in leaves (Sanpera-Calbet et al. 2016).

Within an ecological stoichiometry framework, organisms have been proposed to be homeostatic, meaning that they must maintain their body $\mathrm{C}: \mathrm{N}: \mathrm{P}$ ratios within a narrow range. Therefore, reductions in resource quality, expressed as $\mathrm{C}$ : nutrient ratios, are expected to increase consumer-resource imbalances and thus constrain growth (Sterner and Elser 2002). Many studies have supported this hypothesis, both for aquatic detritivores and herbivores (Stelzer and Lamberti 2002; Frost and Elser 2002a; MasMartí et al. 2015) and for changes in nitrogen and phosphorous concentrations (Iversen 1974; Kendrick and Benstead 2013). Therefore, bottom-up effects of drought through changes in resource quality could lead to differences in growth rates and secondary production in temporary versus permanent streams. Organisms might compensate nutrient deficiences by increasing ingestion (i.e. compensatory feeding), thus maintaining their homeostasis and growth (Frost et al. 2005; Fink and Von Elert 2006; Flores et al. 2014). Nevertheless, reduced microbial conditioning and food quality have also been observed to dampen detritivore ingestion rates when fed on low quality leaves (Aßmann et al. 2011; Danger et al. 2012; Graça and Poquet 2014). Therefore, differences in the responses of organisms to stream drying can be expected.

This study aimed to elucidate how simulated streambed drying (i) alters the quality of benthic resources and (ii) how this affects consumers' consumption, body chemical composition and growth after rewetting. In order to achieve this goal, leaves and epilithic biofilm were exposed to different drying regimes (in the field) and were later offered to a shredder and a scraper, respectively, in the lab. We hypothesised that compared to permanent flow, drying would (i) reduce resource quality by lowering microbial conditioning and (ii) changes would be more pronounced in biofilm, due to its lower water retention capacity, than in leaves contained in leaf packs. Flow recovery was expected to allow increases in resource quality, especially in epilithic biofilm, but to a lesser extent than in resources conditioned under continuous flow. Therefore, after a dry period, impaired food quality and palatability were expected. Unless compensated by increased consumption rates, lower food quality would lower consumer growth rates, and we expected differences between functional feeding groups.

\section{Methods}

Black poplar (Populus nigra L.) leaves and epilithic biofilm were conditioned under different regimes of simulated flow intermittency and changes in their quality were assessed. In order to evaluate the effects of the resulting quality on consumers' consumption, chemical composition and growth, conditioned leaves and biofilm were offered to the potential stream consumers in a laboratory feeding trial.

\section{Resource conditioning}

Resource conditioning (both leaves and biofilm) was conducted from October to December 2010 in Fuirosos $\left(41^{\circ} 41^{\prime} 20^{\prime \prime} \mathrm{N}, 2^{\circ} 34^{\prime} 25^{\prime \prime} \mathrm{E} ; 154 \mathrm{~m}\right.$ a.s.l), a temporary thirdorder Mediterranean stream located in the MontnegreCorredor Natural Park (NE Iberian Peninsula). Monthly mean temperature ranges from $4{ }^{\circ} \mathrm{C}$ (December) to $28^{\circ} \mathrm{C}$ (July-August) and precipitation (650 $\mathrm{mm} \mathrm{year}^{-1}$ ) mostly occurs in autumn and spring with occasional storms in summer (Bernal et al. 2002). Baseline water flow ranges from 5 to $20 \mathrm{~L} \mathrm{~s}^{-1}$, although in summer flow usually ceases from July/August to September/October (Sabater et al. 2011). This oligotrophic stream is surrounded by dense riparian vegetation dominated, in the study reach, by alder (Alnus glutinosa L.), black poplar (Populus nigra L.) and hazel (Corylus avellana L.). The main terrestrial organic matter input from the riparian vegetation occurs between summer (due to water stress in the riparian forest) and autumn (Sanpera-Calbet et al. 2016). During the conditioning period, oxygen $\left(\mathrm{O}_{2}\right), \mathrm{pH}$, temperature and conductivity were measured weekly in the field with portable meters (Hach multi HQ40d, Loveland, U.S.A. and Cond 340i/SET, WTW, Weilheim, Germany) (Table 1).

Air-dried stalkless $P$. nigra leaves, collected within the same catchment after abscission, were weighed $(4 \pm 0.5 \mathrm{~g})$ and enclosed in 5-mm mesh, tetrahedral-shaped bags. Glass tiles $\left(102 \mathrm{~cm}^{2}\right)$ fixed with neutral silicone on concrete blocks were used as coarse substrata surrogates for biofilm colonization. Conditioning of the resources varied (Fig. 1): Permanent flow (PERM), intermittent flow (INT), and no flow (DRY, only for leaves). Leaf packs and tiles under the PERM treatment were randomly placed in different stream 
Table 1 Physicochemical characteristics of the study reach during the conditioning period

\begin{tabular}{lrc}
\hline Parameter & Mean & $\pm \mathrm{SE}$ \\
\hline Conductivity $\left(\mu \mathrm{S} \mathrm{cm}{ }^{-1}\right)$ & 187.4 & \pm 3.3 \\
$\mathrm{pH}$ & 8.1 & \pm 0.1 \\
$\mathrm{O}_{2}\left(\mathrm{mg} \mathrm{L}^{-1}\right)$ & 11.2 & \pm 0.3 \\
$\mathrm{O}_{2}(\%)$ & 96.6 & \pm 0.7 \\
Flow $\left(\mathrm{L} \mathrm{s}^{-1}\right)$ & 22.9 & \pm 3.1 \\
Water temperature $\left({ }^{\circ} \mathrm{C}\right)$ & 8.1 & \pm 0.7 \\
Air temperature $\left({ }^{\circ} \mathrm{C}\right)$ & 9.0 & \pm 0.4 \\
Rainfall $\left(\mathrm{mm} \mathrm{d}^{-1}\right)$ & 2.4 & \pm 1.3 \\
\hline
\end{tabular}

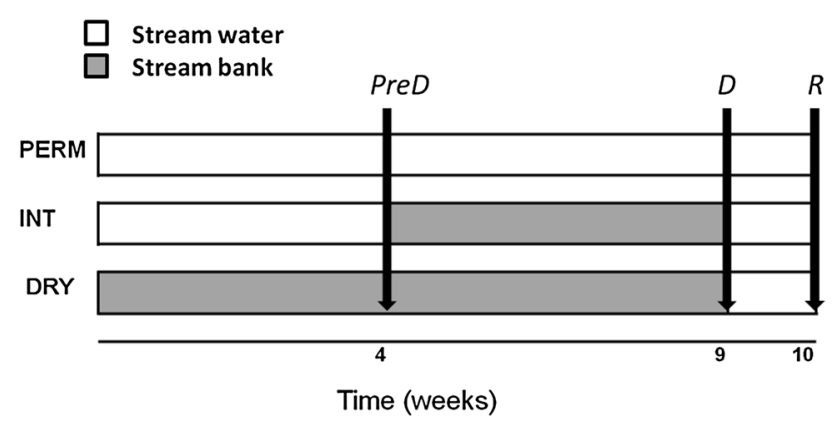

Fig. 1 Experimental design showing the number of weeks resources were conditioned in the stream (in white) or exposed on the stream bank (in grey) for the different conditioning treatments [permanent flow (PERM), intermittent flow (INT), and dry flow (DRY, only for leaves)]. Vertical arrows indicate the three sampling dates during the conditioning phase: predry (PreD), dry (D) and upon rewetting (R)

riffles where they were allowed to condition for 10 weeks. In the intermittent flow (INT) treatment, resources that had been in the stream channel for 4 weeks were transferred to the stream bank for 5 more weeks, simulating an intermittent dry period in the stream. They were subsequently resubmerged and allowed to condition for a final week in the stream channel. Finally, to simulate terrestrial exposure to a long period of drought after abscission, leaves under the DRY treatment were left on the stream bank for 9 weeks and then submerged in the stream to allow 1 week of instream conditioning. Several small rainfall events were recorded during the conditioning period (Table 1) but only two events $(<1 \mathrm{~mm})$ when leaves were on the stream bank. New sets of leaf bags and tiles (i.e. time blocks) were conditioned at 1-week intervals (two sets for biofilm and four for leaves) according to the schedule of each treatment (described above), in order to provide freshly conditioned resources to consumers throughout the feeding trial.

Leaves and biofilm were sampled on three occasions during the conditioning period (i.e. conditioning phase): (i) one after 4 weeks of conditioning, prior to retrieval of INT resources from the stream (PreD; Predry phase); (ii) one after 9 weeks, just before returning the INT and DRY resources to the stream water (D; Dry phase) and (iii) at the end of the conditioning period, after 10 weeks (R; Rewetting phase) (Fig. 1). Four replicates per resource type and treatment were taken on the first two sampling dates (PreD and D) and five replicates were taken on the last sampling date (R). After retrieval, leaf bags and glass tiles were individually enclosed in ziplock bags and transported to the laboratory in a cooler where they were gently rinsed with distilled water.

Glass tiles were immersed in a known volume of distilled water, scraped with a toothbrush and sonicated $(2+2 \mathrm{~min}$, Selecta sonication bath at $150 \mathrm{~W}$ and $50 \mathrm{~Hz}$ ) to obtain the epilithic biofilm. For chlorophyll $a$ determination, an aliquot of the extracted and homogenized biofilm was filtered (GF/F Whatman). Similarly, leaf biofilm from five poplar discs (12-mm diameter) was scraped with a toothbrush and also filtered (Whatman GF/F). An extra set of five poplar discs was cut on the last sampling date (R) for determination of fungal biomass. Samples were frozen $\left(-20^{\circ} \mathrm{C}\right)$ until analysis. The remaining poplar leaves (excluding the main vein) and epilithic biofilm extract were lyophilized, ground and used for carbon $(\mathrm{C})$, nitrogen $(\mathrm{N})$, phosphorus $(\mathrm{P})$ and lipid determination (see below).

\section{Feeding experiments}

Experiments were performed with similar-sized individuals of the shredder Stenophylax sp. (Trichoptera, Limnephilidae; mean $\pm \mathrm{SE}$ of head width, $1.90 \pm 0.02 \mathrm{~mm}$ ) and the scraper Physella acuta Draparnaud (Mollusca, Physidae; mean \pm SE of soft body dry mass, $2.65 \pm 0.13 \mathrm{mg}$ ), both of them common in Mediterranean streams (Bonada et al. 2004; Tierno de Figueroa et al. 2013). Stenophylax were collected from the stream (Fuirosos) in which the resources were conditioned. Physella, also present in Fuirosos, were collected from a nearby stream within the same catchment due to their low abundance at the time of collection at the study site. 3 days before the start of the experiment, consumers were transported to the laboratory in plastic containers with stream water and sand. In the laboratory, individuals were acclimatized at $8{ }^{\circ} \mathrm{C}$ (average temperature of the study reach during the conditioning period; Table 1), under an $8 \mathrm{~h}$ light: $16 \mathrm{~h}$ dark photoperiod, and fed either conditioned alder litter (for Stenophylax) or epilithic biofilm (for Physella) ad libitum. $24 \mathrm{~h}$ prior to the start of the experiment, individuals were starved to allow evacuation of their gut contents.

For the experiment, Stenophylax $(\mathrm{n}=30)$ were individually allocated to glass microcosms $(8.5 \mathrm{~cm}$ diameter $\times 9 \mathrm{~cm}$ high) containing $250 \mathrm{~mL}$ of filtered stream water and provided with ashed stream sediment $\left(\varnothing 0.5-2 \mathrm{~mm} ; 450^{\circ} \mathrm{C}\right.$ $4 \mathrm{~h})$ to allow the larvae to build their cases. Physella 
$(\mathrm{n}=40)$ were also individually allocated to plastic microcosms $(21 \times 14 \times 6.5 \mathrm{~cm})$ containing $615 \mathrm{~mL}$ of filtered stream water. Water in the microcosms was oxygenated using an air-pump for the duration of the experiment and, like sediment, was replaced every 3 days to avoid ammonia accumulation and to compensate for water loss.

\section{Consumers' consumption and growth}

Thirty premeasured Stenophylax (head width, stereoscopic microscope at $\times 10$ ) were individually allocated to microcosms and randomly split into three groups (10 individuals per treatment). Each individual was fed with 20 PERM, INT or DRY preconditioned poplar discs (12-mm diameter). Five extra microcosms per treatment, containing 20 leaf discs but no animals, were used as a control for leaf mass changes other than as a result of invertebrate consumption. Every week for 4 weeks, any remaining leaf material was removed and replaced with 20 new freshly conditioned leaf discs. The removed leaf discs were collected, dried at $60^{\circ} \mathrm{C}$ until constant weight, and weighed. Leaf dry mass (DM) offered to invertebrates was estimated from extra sets of conditioned (PERM, INT and DRY) leaves at each replacement. At the end of the experiment, individual head width were measured again.

Physella were also premeasured (shell length with a digital calliper) and similar sized individuals allocated to microcosms and randomly split into two groups (20 individuals per treatment). Each individual was given either PERM or INT conditioned glass tiles. Five extra microcosms per treatment, containing glass tiles but no animals, were used as a control for chlorophyll $a$ changes other than as a result of invertebrate consumption. After 1 week, the tiles were removed and replaced with two new freshly conditioned tiles. The biofilm remaining on the removed tiles was scraped off with a toothbrush and an aliquot of the extracted and homogenized biofilm was filtered (GF/F Whatman) for chlorophyll analysis. The chlorophyll content of the biofilm offered to scrapers was estimated from extra conditioned (PERM or INT) glass tiles.

At the end of the experiment (28 days for Stenophylax and 14 days for Physella), surviving individuals were freezed-dried, weighed to the nearest $0.01 \mathrm{mg}$, ground and individually used for C, N, P and lipid content evaluation as described below. Survivorship was recorded every 3 days throughout the experiment.

Consumption (C) was calculated as the loss of leaf DM or biofilm chlorophyll corrected by DM or chlorophyll loss in the control microcosms of the respective treatments. The relative consumption rate (RCR) was calculated as $R C R=C l\left(D M_{\text {cons }} \times\right.$ day $)$, where $D M_{\text {cons }}$ is the consumer's $\mathrm{DM}(\mathrm{mg})$ at the end of the experiment and day is the duration of the test in days.
Stenophylax relative growth rates $(R G R)$ were estimated as $R G R=H W_{f}-H W_{i} /(H W \times$ day $)$, where $H W_{f}$ and $H W_{i}$ are the final and initial head width (mm), $H W$ is the mean head width between the start and the end of the test and day is the number of days the test lasted. Physella RGR was calculated as $R G R=D M_{f}-D M_{i} /\left(D M_{f} \times\right.$ day $)$, where $D M_{f}$ and $D M_{i}$ are the final and initial soft body DM $(\mathrm{mg})$ and day is the duration of the test. Soft body DM at the beginning of the experiment was estimated from 15 extra individuals randomly selected from the initial pool.

\section{Chemical analysis}

Chlorophyll $a$ was extracted in $90 \%$ acetone for $12 \mathrm{~h}$ in the dark at $4{ }^{\circ} \mathrm{C}$ after a 2-min sonication (Selecta sonication bath at $150 \mathrm{~W}$ and $50 \mathrm{~Hz}$ ). Afterwards, samples were further sonicated to ensure complete chlorophyll extraction. After filtration (GF/C Whatman) of the extract, the chlorophyll concentration was determined spectrophotometrically (Lambda 2 UV/VIS spectrophotometer, Perkin-Elmer) following Jeffrey and Humphrey (1975).

Fungal biomass in conditioned poplar leaves was estimated by ergosterol analysis. Ergosterol was extracted from lyophilized leaf discs using $\mathrm{KOH}$ methanol $0.14 \mathrm{M}$ at $80^{\circ} \mathrm{C}$ for $30 \mathrm{~min}$, and then separated by solid-phase extraction (Waters Sep-Pack ${ }^{\circledR}$ Vac RC, 500 mg, tC18 cartridges, Waters Corp., Milford, MA, USA; Gessner and Schmitt 1996). Ergosterol was quantified by HPLC-MS/ MS (HPLC Agilent 1100 series, Waldbronn, Germany; Headley et al. 2002) equipped with a API 3000 triplequadrupole mass spectrometer (PE Sciex, Concord, ON, Canada). The mobile phase was $100 \%$ methanol at a flow rate of $450 \mu \mathrm{min}^{-1}$. Separation was achieved in a Luna $5 \mu \mathrm{m} \mathrm{c} 18,100 \mathrm{~A}, 150 \times 2 \mathrm{~mm}$ analytical column (Phenomenex, Torrance, CA, USA). Quantification was performed via a multiple reaction monitoring (MRM) method at $\mathrm{m} / \mathrm{z}$ $379.1 / 69.1$ and conversion to fungal biomass was achieved using a conversion factor of $5.5 \mu \mathrm{g}$ ergosterol $\mathrm{mg}^{-1}$ fungal DM (Gessner 1997).

$\mathrm{C}$ and $\mathrm{N}$ contents were analysed in a Thermo Elemental Analyser 1108 (Thermo Scientific, Milan, Italy). Total $\mathrm{P}$ concentration was determined after a basic digestion $(\mathrm{NaOH})$ of samples in an autoclave $\left(110^{\circ} \mathrm{C}\right.$ for $\left.90 \mathrm{~min}\right)$ (Koroleff and Weinheimer 1983) and subsequent determination of total phosphate concentrations (P-PO4) using the ascorbic acid method (APHA 1989).

For lipid analyses, samples were homogenized with an ultrasonic homogenizer $(200 \mathrm{~W}, 24 \mathrm{kHz}$; Hielscher UltrasonicsGmbH, Teltow, Germany) and lipids extracted with a mixture of chloroform and methanol (2:1) according to Bligh and Dyer (1959). The total lipid content was analysed using the colorimetric sulphophosphovanillin method (Zollner and Kirsch 1962). 


\section{Data analysis}

The effects of conditioning treatment and conditioning phase on leaf and biofilm quality (i.e. chlorophyll, \%, $\mathrm{N}$ and $\mathrm{P}$ and their molar ratios and lipid concentration) were analysed using a mixed linear model with conditioning treatment and conditioning phase as fixed and crossed factors and set of leaf bags or biofilm tiles (i.e. time block) as a random factor. In order to test for differences in resource quality offered to consumers, a mixed linear model including only samples from the last sampling date (R) was used, considering conditioning treatment as the fixed factor and set of leaf bags or biofilm tiles (i.e. block) as a random factor. The restricted maximum likelihood estimation (REML) method was used to test both models.

The effects of resource quality (i.e. conditioning treatment) on the chemical composition (i.e.\% C, N and P, their molar ratios and lipid concentration) and performance (consumption and growth) of Stenophylax and Physella were first analysed by one-way ANCOVA, with conditioning treatment as factor and individual DM as a covariate. When the covariate was not significant, it was removed from the model, and one-way ANOVA was used.
Data were log-transformed when necessary to achieve normality and homoscedasticity, which were checked by visual inspection of the residual distributions. Tukey's posthoc multicomparison tests were applied when significantly different effects were found. For all analyses a significance level of 0.05 was established. ANOVA and ANCOVA analyses were performed using IBM SPSS Statistics 20 software for Windows (SPSS Inc., Chicago, IL, USA) and the mixed linear models using the software $\mathrm{R}$, version 2.13.2 ( $\mathrm{R}$ Development Core Team 2011); and the R package nlme (Pinheiro et al. 2017).

\section{Results}

\section{Effects of drying on resource quality}

Leaf conditioning treatment significantly affected poplar leaf quality (Table 2a; Fig. 2, changes in dry mass in Fig. $\mathrm{S} 1)$. Percentage of $\mathrm{N}$ was significantly lower in DRY leaves (Table 2a; Fig. 2b), which resulted in higher C:N and lower $\mathrm{N}: \mathrm{P}$ ratios than in PERM or INT leaves (Fig. 2e, g). Percentage of $\mathrm{P}$ was higher in DRY leaves, although 1 week

Table 2 Results of the mixed linear model for conditioning treatment and phase effects on leaf and biofilm quality parameters (a; treatment $x$ phase) and for differences in conditioned leaf and biofilm offered to consumers [b; treatment at rewetting (R)]

\begin{tabular}{|c|c|c|c|c|c|c|c|c|}
\hline \multirow{3}{*}{$\begin{array}{l}\text { Variable } \\
\text { Leaves }\end{array}$} & \multicolumn{6}{|l|}{ (a) } & \multirow{2}{*}{\multicolumn{2}{|c|}{$\begin{array}{l}\text { (b) } \\
\text { Treatment at rewet- } \\
\text { ting }(\mathrm{R})\end{array}$}} \\
\hline & \multicolumn{2}{|c|}{ Treatment } & \multicolumn{2}{|l|}{ Phase } & \multicolumn{2}{|c|}{ Treatment $\times$ phase } & & \\
\hline & $\mathrm{F}_{2,144}$ & $P$ & $\mathrm{~F}_{2,144}$ & $\mathrm{P}$ & $\mathrm{F}_{4,144}$ & $P$ & $\mathrm{~F}_{2,54}$ & $P$ \\
\hline $\mathrm{C}(\%)$ & 26.690 & $<0.001$ & 17.640 & $<0.001$ & 2.140 & 0.079 & 30.160 & $<\mathbf{0 . 0 0 1}$ \\
\hline $\mathrm{N}(\%)$ & 88.405 & $<0.001$ & 11.140 & $<0.001$ & 1.199 & 0.314 & 26.956 & $<0.001$ \\
\hline $\mathrm{P}(\%)$ & 3.956 & 0.021 & 1.219 & 0.299 & 2.416 & 0.051 & 3.043 & 0.056 \\
\hline $\mathrm{C}: \mathrm{N}$ & 134.676 & $<0.001$ & 5.733 & 0.004 & 0.724 & 0.577 & 47.925 & $<0.001$ \\
\hline $\mathrm{C}: \mathrm{P}$ & 1.429 & 0.243 & 0.482 & 0.619 & 2.457 & 0.048 & 2.630 & 0.082 \\
\hline $\mathrm{N}: \mathrm{P}$ & 71.899 & $<0.001$ & 2.518 & 0.084 & 3.112 & & 22.384 & $<0.001$ \\
\hline Lipids (\%) & 1.523 & 0.222 & 6.436 & 0.002 & 2.128 & 0.080 & 0.776 & 0.465 \\
\hline Chlorophyll $\left(\mu \mathrm{g} \mathrm{cm}^{-2}\right)$ & 47.419 & $<0.001$ & 1.678 & 0.190 & 5.892 & $<0.001$ & 14.879 & $<0.001$ \\
\hline Fungal biomass (mg g DM-1) & - & - & - & - & - & - & 14.300 & $<0.001$ \\
\hline Biofilm & $\mathrm{F}_{1,45}$ & $P$ & $\mathrm{~F}_{2,45}$ & $P$ & $\mathrm{~F}_{2,45}$ & $P$ & $\mathrm{~F}_{1,17}$ & $P$ \\
\hline $\mathrm{C}(\%)$ & 2.118 & 0.153 & 0.815 & 0.449 & 0.169 & 0.845 & 0.327 & 0.575 \\
\hline $\mathrm{N}(\%)$ & 1.243 & 0.271 & 2.847 & 0.069 & 3.275 & 0.047 & 7.730 & 0.013 \\
\hline $\mathrm{P}(\%)$ & 0.873 & 0.355 & 2.369 & 0.105 & 0.371 & 0.692 & 2.138 & 0.162 \\
\hline $\mathrm{C}: \mathrm{N}$ & 7.371 & 0.009 & 2.814 & 0.071 & 3.060 & 0.057 & 6.422 & 0.021 \\
\hline $\mathrm{C}: \mathrm{P}$ & 3.830 & 0.057 & 3.459 & 0.040 & 0.026 & 0.975 & 1.978 & 0.178 \\
\hline $\mathrm{N}: \mathrm{P}$ & 0.077 & 0.783 & 3.574 & $\mathbf{0 . 0 3 7}$ & 2.006 & 0.147 & 2.419 & 0.138 \\
\hline Lipids (\%) & 2.302 & 0.136 & 10.182 & $<0.001$ & 2.161 & 0.127 & 3.972 & 0.064 \\
\hline Chlorophyll $\left(\mu \mathrm{g} \mathrm{cm}^{-2}\right)$ & 56.806 & $<\mathbf{0 . 0 0 1}$ & 6.740 & 0.003 & 21.613 & $<0.001$ & 15.890 & 0.001 \\
\hline
\end{tabular}

Values $<0.050$ are indicated in boldface type and those $<0.100$, in italics

All ratios are molar ratios 

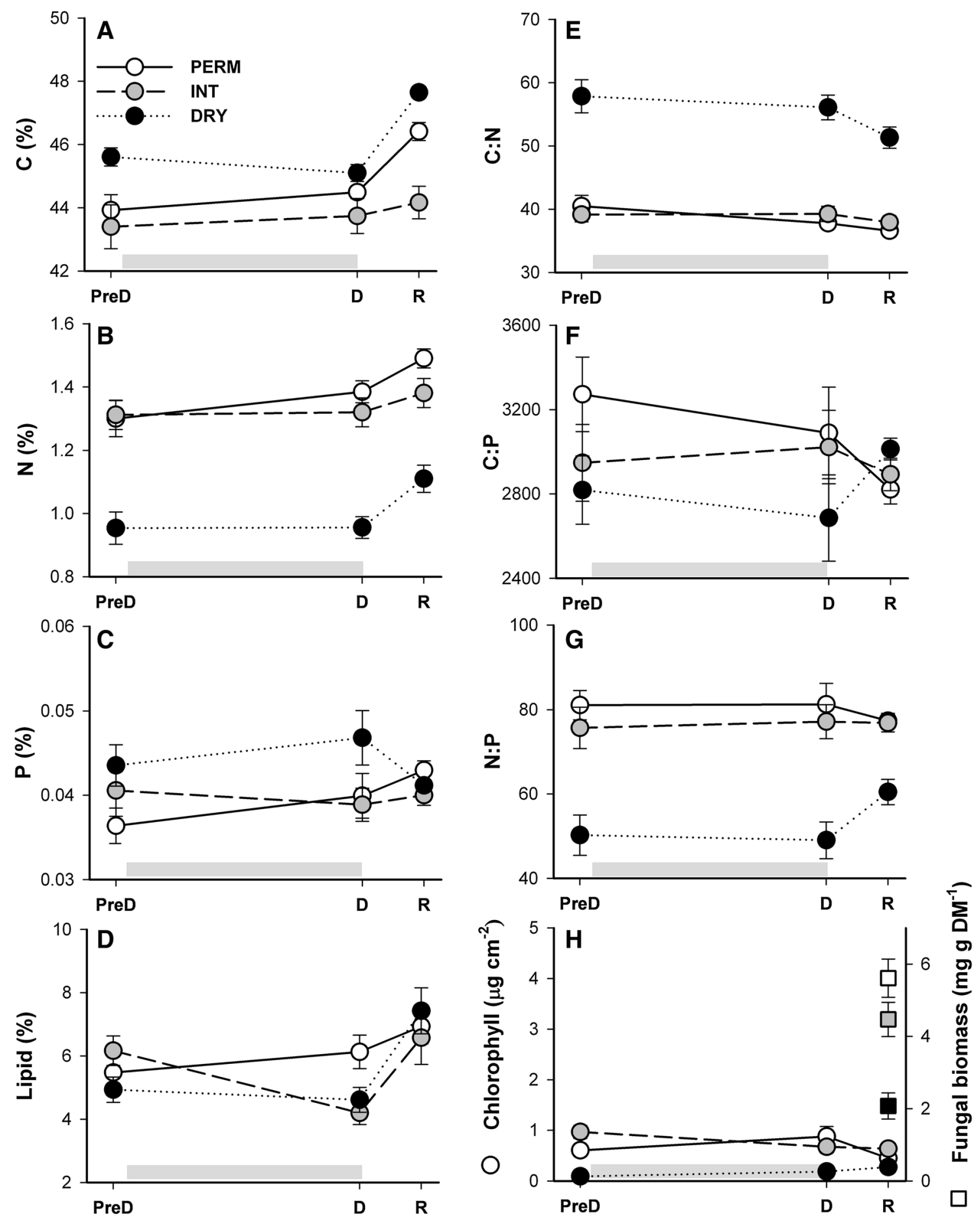

\section{Conditioning Phase}

Fig. 2 Effects of flow conditioning treatment [permanent flow (PERM), intermittent flow (INT), and dry flow (DRY)] and phase [predry (PreD), dry (D) and upon rewetting (R)] on poplar leaf

of instream conditioning was sufficient to achieve lower values of $\% \mathrm{P}$ similar to those of PERM and INT leaves (Fig. 2c). \%C was also significantly higher in DRY leaves quality parameters. Values are means $\pm \mathrm{SE}$ of the four leaf trials $(n=16-20)$ at each phase. The shaded area corresponds to the period when the INT treatment was not submerged in the stream water

(Table 2a), though PERM leaves had intermediate values at the end of the conditioning period (Fig. 2a). Lipid percentage significantly dropped in leaves under a dry regime 
but rapidly recovered after 1 week of rewetting (Table 2a; Fig. 2d). Chlorophyll concentration was significantly lower for DRY leaves (Table 2a), in which it increased slightly on the third sampling date (Table 2a; Fig. 2h).

The drying treatment also caused changes in biofilm quality and quantity (Table 2a; Fig. 3). When conditioned under INT conditions, biofilm had higher $\mathrm{C}: \mathrm{N}$ ratios and lower chlorophyll content than in the other conditions (Fig. 3e, h). As expected, chlorophyll concentration decreased in the INT treatment during the dry phase, and although 1 week of instream conditioning raised levels to those of the predrying conditioning, values after rewetting were significantly lower than in PERM biofilm (Table 2a; Fig. 3h). Similarly, $\% \mathrm{~N}$ decreased in INT biofilm during the dry phase. However, after one more week of instream conditioning, $\% \mathrm{~N}$ continued decreasing, becoming significantly lower than that in PERM biofilm (Table 2a; Fig. 3b). $\mathrm{N}: \mathrm{P}$ and $\mathrm{C}: \mathrm{P}$ ratios varied through the conditioning period for both treatments, following $\mathrm{N}$ and $\mathrm{C}$ dynamics (Fig. 3a, $\mathrm{b}, \mathrm{f}, \mathrm{g})$. Lipid percentage increased upon rewetting in both treatments (Fig. 3d).

At the end of the conditioning period ( $\mathrm{R}$ phase), when resources were offered to consumers, DRY leaves contained a significantly lower proportion of chlorophyll and fungal biomass (Fig. 2h) and N, which resulted in higher $\mathrm{C}: \mathrm{N}$ and lower $\mathrm{N}: \mathrm{P}$ ratios (Table 2b). In contrast, INT leaves resembled PERM leaves, except for a lower C\% and a non-significant tendency for a lower $\mathrm{P}$ concentration (Table 2b). Finally, biofilm under the INT treatment had a lower chlorophyll concentration, higher $\mathrm{C}: \mathrm{N}$ ratios and a tendency to a lower \% lipid (Table 2b).

\section{Effects on consumers' tissue chemistry and performance}

Stenophylax fed with DRY leaves were enriched with $\mathrm{P}$ which also resulted in significant lower C:P and N:P ratios (Table 3). There was also a tendency for DRY shredders to have a lower $\% \mathrm{~N}$ (Table 3). On the contrary, there were no differences in Physella stoichiometry at the end of the experiment (Table 3). No changes in \%lipid were observed for any of the species (Table 3).

Stenophylax fed on PERM leaves showed the highest consumption and growth rates (Table 4; Fig. 4a, b). The growth rates of Stenophylax fed on PERM leaves were significantly higher than in those fed on INT leaves (Table 4; Fig. 4c). No mortality was observed during the experiment.

Physella fed on PERM biofilm had significantly higher consumption rates than those fed on INT biofilm (Table 4; Fig. 4c). Surprisingly, there were no differences in growth rates (Table 4; Fig. 4d) or mortality (44 and 40\% for PERM and INT treatment, respectively) between treatments.

\section{Discussion}

As hypothesized, drying affected resource quality, and the observed effects were more severe on biofilm than leaves. In fact, when instream conditioning was interrupted for 5 weeks, after 1 week of rewetting, INT leaves resembled continuously submerged leaves (PERM) much more than terrestrially conditioned ones (DRY), indicating that the conditions within leaf packs might have conferred resistance to ambient drying on presubmerged leaves. However, impacts on epilithic biofilms could still be observed after 1 week of rewetting, resulting in higher $\mathrm{C}: \mathrm{N}$ ratios and a decrease in chlorophyll content, characteristics that were also observed in DRY leaves.

In agreement with our predictions, drying greatly affected algal biomass, but only in epilithic biofilms. The higher C:N ratios observed in this study are likely to be related to chlorophyll degradation, which have been positively related to a decrease in leucine-aminopeptidase activity during desiccation in seasonal summer drought (Timoner et al. 2012). Although in some cases a rapid recovery (within hours) of algal biomass has been reported after flow resumption (Romaní et al. 2013), it has also been related to nutrients wash from the dried streambed or watershed after flow resumption (Bernal et al. 2002), which did not take place in our experiment.

Leaf quality was also affected by drying when instream conditioning was prevented (DRY treatment). Under terrestrial conditioning, both algal and fungal colonization of leaves were lower, which is consistent with the lower decomposition rates in terrestrial than aquatic ecosystems described elsewhere (Boulton and Lake 1992; Langhans et al. 2008; Bruder et al. 2011). Prior to submersion, DRY leaves had a lower lipid and \% $\mathrm{N}$ but higher \% P. However, after 1 week of stream conditioning lipid and $\mathrm{P}$ concentrations equalled those of PERM and INT leaves, probably due to the rapid leaching of $\mathrm{P}$ from air-dried leaves when first submerged in water (Gessner 1991). In contrast, although this period allowed a certain amount of chlorophyll and $\mathrm{N}$ accrual in DRY leaves, their concentration, as well as fungal biomass, remained significantly lower in comparison to PERM and INT leaves. This lower $\mathrm{N}$ concentration in DRY leaves could reflect a lower microbial biomass as both chlorophyll and fungal biomass are $\mathrm{N}$-enriched in comparison with senescent leaves (Graça 2001; Sterner and Elser 2002). Alternatively, the only observed effect of drying on previously submerged leaves (INT treatment, D phase) was a decrease in lipid concentration, which was rapidly restored after rewetting. Because the experiment was conducted in autumn, mild air temperatures and the presence of a small amount of rainfall (Table 1) might have allowed humidity retention within leaf packs, which might have acted as a humid refuge for microorganisms (Romaní et al. 

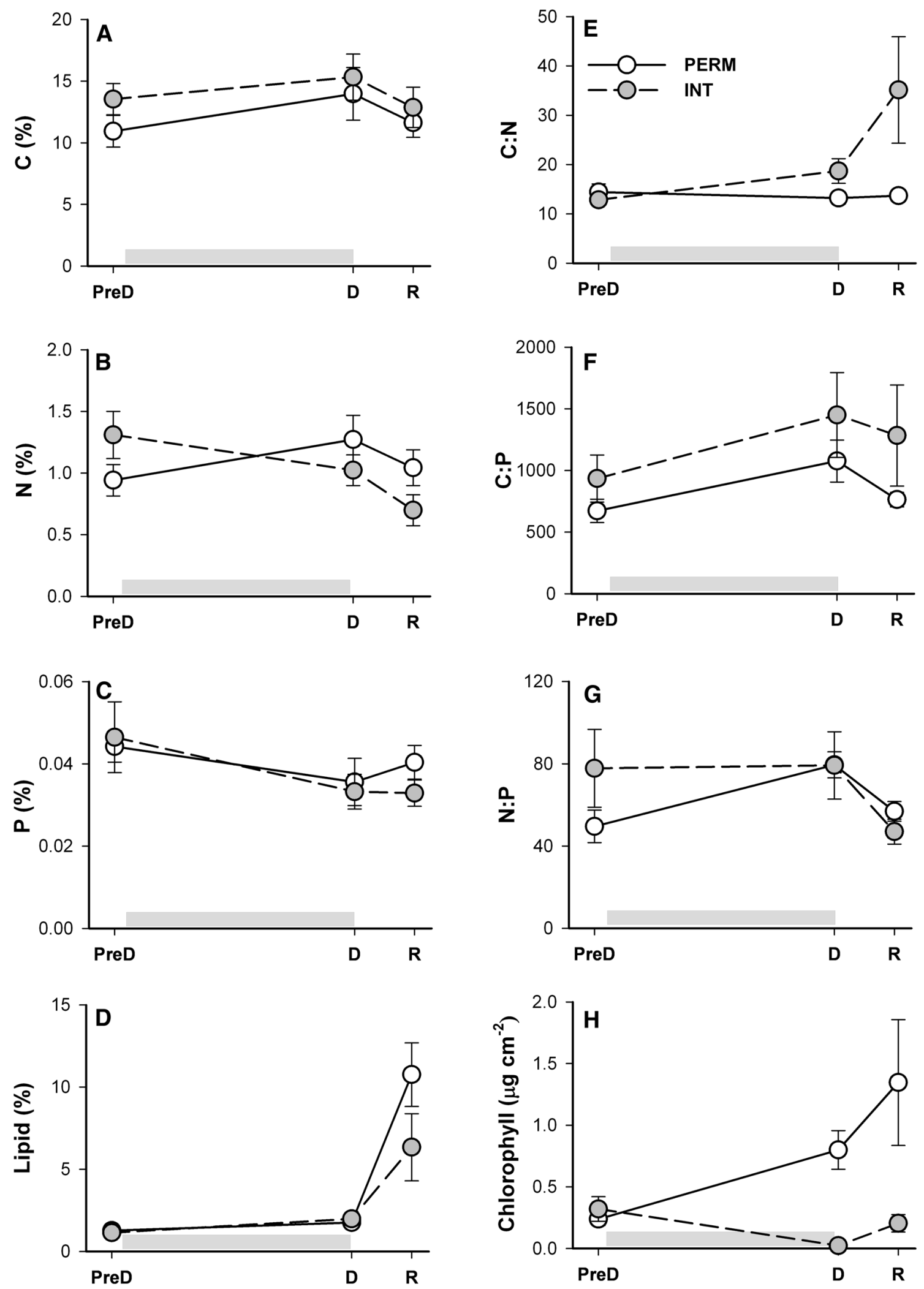

\section{Conditioning Phase}

Fig. 3 Effects of flow conditioning treatment [permanent flow (PERM), intermittent flow (INT)] and phase [predry (PreD), dry (D) and upon rewetting $(\mathrm{R})]$ on biofilm quality parameters. Values are means \pm SE of the four biofilm trials $(n=8-10)$ at each phase. The shaded area corresponds to the period when the INT treatment was not submerged in the stream water 
Table 3 Mean $( \pm$ SE) and results of ANCOVA or ANOVA of effects of leaf and biofilm conditioning [permanent flow (PERM), intermittent flow (INT), and dry flow (DRY, only for leaves)] on consumers' (Stenophylax and Physella, respectively) stoichiometry and \%lipid

\begin{tabular}{|c|c|c|c|c|c|c|c|c|c|c|}
\hline \multirow{3}{*}{$\begin{array}{l}\text { Variable } \\
\text { Stenophylax }\end{array}$} & \multicolumn{6}{|c|}{ Mean $( \pm$ SE) } & \multicolumn{4}{|c|}{ Statistics } \\
\hline & \multicolumn{2}{|l|}{ PERM } & \multicolumn{2}{|l|}{ INT } & \multicolumn{2}{|l|}{ DRY } & \multicolumn{2}{|c|}{ Treatment } & \multicolumn{2}{|c|}{ DM (covar) } \\
\hline & \multicolumn{2}{|l|}{$n=4$} & \multicolumn{2}{|l|}{$n=4$} & \multicolumn{2}{|l|}{$n=4$} & \multirow{2}{*}{$\frac{F_{2,8 / 2,9^{a}}}{0.224}$} & \multirow{2}{*}{$\frac{P}{0.804}$} & \multirow{2}{*}{$\frac{\mathrm{F}_{1,8}}{14.638}$} & \multirow{2}{*}{$\begin{array}{l}P \\
0.005\end{array}$} \\
\hline $\mathrm{C}(\%)$ & 48.26 & $( \pm 1.32)$ & 47.26 & $( \pm 1.30)$ & 47.78 & $( \pm 1.30)$ & & & & \\
\hline $\mathrm{N}(\%)$ & 10.18 & $( \pm 0.27)$ & 10.21 & $( \pm 0.06)$ & 9.02 & $( \pm 0.58)$ & 3.393 & 0.080 & - & - \\
\hline $\mathrm{P}(\%)$ & 0.64 & $( \pm 0.05)$ & 0.65 & $( \pm 0.07)$ & 0.82 & $( \pm 0.01)$ & 4.921 & 0.051 & - & - \\
\hline $\mathrm{C}: \mathrm{N}$ & 5.63 & $( \pm 0.18)$ & 5.37 & $( \pm 0.14)$ & 6.32 & $( \pm 0.429)$ & 3.224 & 0.088 & - & - \\
\hline $\mathrm{C}: \mathrm{P}$ & 200.60 & $( \pm 13.48)^{\mathrm{a}}$ & 190.83 & $( \pm 15.34)^{\mathrm{ab}}$ & 151.27 & $( \pm 1.94)^{\mathrm{b}}$ & 4.864 & 0.037 & - & - \\
\hline $\mathrm{N}: \mathrm{P}$ & 36.01 & $( \pm 3.74)^{\mathrm{a}}$ & 35.81 & $( \pm 3.65)^{\mathrm{a}}$ & 24.27 & $( \pm 1.75)^{\mathrm{a}}$ & 4.466 & 0.045 & - & - \\
\hline Lipid (\%) & 4.00 & $( \pm 0.48)$ & 3.46 & $( \pm 0.48)$ & 4.61 & $( \pm 0.48)$ & 2.265 & 0.166 & 15.988 & 0.004 \\
\hline \multirow[t]{3}{*}{ Physella } & \multirow[t]{3}{*}{$n=3$} & & & \multirow[t]{3}{*}{$n=3$} & & & \multicolumn{4}{|c|}{ Statistics } \\
\hline & & & & & & \multicolumn{3}{|c|}{ Treatment } & \multicolumn{2}{|c|}{ DM (covar) } \\
\hline & & & & & & \multicolumn{2}{|l|}{$\mathrm{F}_{1,4}$} & $P$ & $\mathrm{~F}_{1,8}$ & $P$ \\
\hline $\mathrm{C}(\%)$ & 44.95 & \multicolumn{2}{|c|}{$( \pm 1.03)$} & 47.22 & $( \pm 1.10)$ & \multicolumn{2}{|l|}{2.280} & 0.206 & - & - \\
\hline $\mathrm{N}(\%)$ & 10.35 & \multicolumn{2}{|c|}{$( \pm 0.35)$} & 11.67 & $( \pm 0.71)$ & \multicolumn{2}{|l|}{2.770} & 0.171 & \multicolumn{2}{|l|}{-} \\
\hline $\mathrm{P}(\%)$ & 0.88 & \multicolumn{2}{|c|}{$( \pm 0.08)$} & 0.84 & $( \pm 0.07)$ & \multicolumn{2}{|l|}{0.114} & 0.752 & \multicolumn{2}{|l|}{-} \\
\hline $\mathrm{C}: \mathrm{N}$ & 5.07 & & & 4.74 & $( \pm 0.18)$ & 2.879 & & 0.165 & - & - \\
\hline $\mathrm{C}: \mathrm{P}$ & 134.10 & & & 146.53 & $( \pm 9.30)$ & 0.848 & & 0.409 & - & - \\
\hline $\mathrm{N}: \mathrm{P}$ & 26.44 & & & 30.84 & $( \pm 0.77)$ & 4.648 & & 0.097 & - & - \\
\hline Lipid (\%) & 6.01 & & & 5.76 & $( \pm 0.57)$ & 0.092 & & 0.777 & - & - \\
\hline
\end{tabular}

$P$ values $<0.050$ are indicated in boldface type and those $<0.100$, in italics

Different letters indicate significant differences (Tukey's HSD, $P<0.050$ )

All ratios are molar ratios

${ }^{a}$ Degrees of freedom for ANCOVA and ANOVA analyses, respectively

Table 4 Results of ANCOVA or ANOVA of effects of leaf and biofilm conditioning on consumers' (Stenophylax and Physella, respectively) relative consumption rate (RCR) and relative growth rate (RGR)

\begin{tabular}{|c|c|c|c|c|c|c|}
\hline \multirow[t]{2}{*}{ Variable } & \multicolumn{3}{|c|}{ Treatment } & \multicolumn{3}{|c|}{ DM (covar) } \\
\hline & $d f$ & $F$ & $P$ & $d f$ & $F$ & $P$ \\
\hline \multicolumn{7}{|l|}{ Stenophylax } \\
\hline $\mathrm{RCR}\left(\mathrm{mg} \mathrm{mg}^{-1} \mathrm{~d}^{-1}\right)$ & 2.23 & 16.037 & $<0.001$ & 1.23 & 57.083 & $<\mathbf{0 . 0 0 1}$ \\
\hline RGR (HW mm HW mm $\mathrm{mm}^{-1} \mathrm{~d}^{-1}$ ) & 2.27 & 3.783 & 0.036 & - & - & - \\
\hline \multicolumn{7}{|l|}{ Physella } \\
\hline $\mathrm{RCR}\left(\mathrm{mg} \mathrm{Chl} \mathrm{mg} \mathrm{m}^{-1} \mathrm{~d}^{-1}\right)$ & 1.13 & 67.058 & $<\mathbf{0 . 0 0 1}$ & - & - & - \\
\hline $\operatorname{RGR}\left(\mathrm{mg} \mathrm{mg}^{-1} \mathrm{~d}^{-1}\right)$ & 1.15 & 0.303 & 0.590 & - & - & - \\
\hline
\end{tabular}

ANOVAs were used after excluding the non-significant $(P>0.100)$ covariable $(D M)$ from the model. Covar stands for covariable, $H W$ for head width and $C h l$ for Chlorophyll

$P$ values $<0.050$ are indicated in boldface
2013). This would be consistent with the slight accrual in chlorophyll observed in DRY leaves prior to stream submergence. Although we only measured fungal biomass at the end of the experiment ( $\mathrm{R}$ phase), the lack of differences between PERM and INT leaves suggests either little effect of desiccation on fungal biomass or a rapid recovery of fungal biomass after rewetting. Another study, involving similar drying conditions but for a shorter duration, found that the effects of stream drying on fungal biomass were dependent on leaf species (alder and oak), the impacts being more obvious in higher quality leaves where colonization was more advanced (Bruder et al. 2011).

Changes in resource conditioning affected detritivore performance. Stenophylax consumption was stimulated when resources had been conditioned under permanent flow, which resulted in the highest growth rates under this 


\section{Stenophylax}
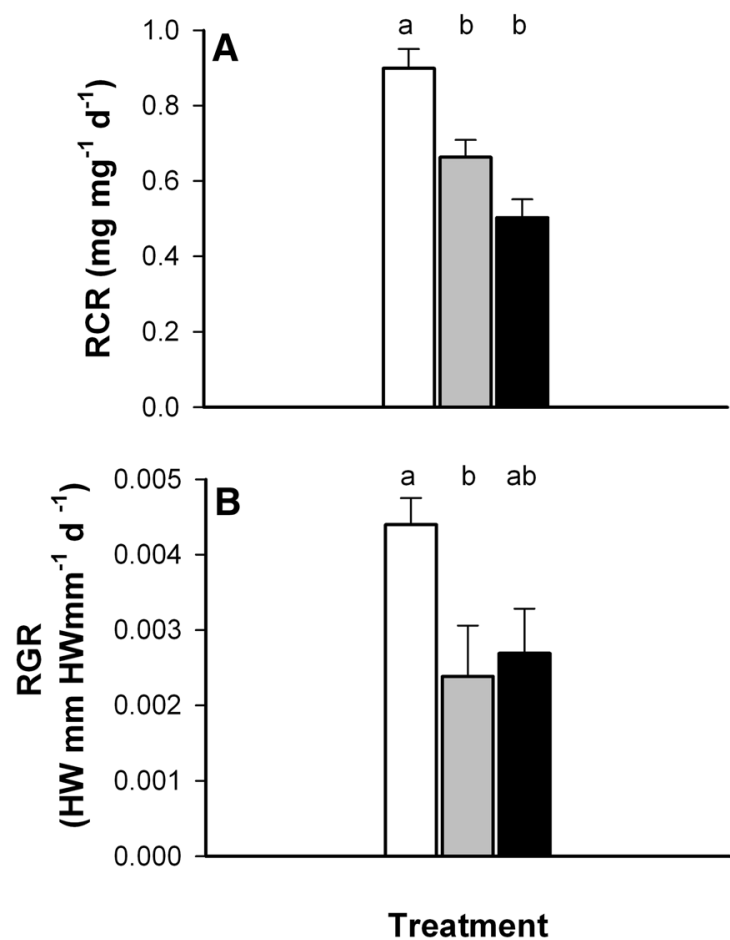

Fig. 4 Effects of leaves and biofilm conditioning [permanent flow (PERM), intermittent flow (INT), and dry flow (DRY, only for leaves)] on consumers' (Stenophylax and Physella, respectively) relative consumption rate (RCR; a $n=9-10$ and $\mathbf{c} n=6-9$ ) and relative

treatment. The reduced consumption of DRY leaves was expected due to their lower conditioning (Cummins and Klug 1979; Graça et al. 2001), the result of reduced microbial metabolism in terrestrial habitats (Molles et al. 1995). Among aquatic detritivores, leaf palatability has been inversely related to leaf toughness and positively related to fungal biomass and $\mathrm{N}$ concentration (Irons et al. 1988; Hladyz et al. 2009; Aßmann et al. 2011), which were significantly lower in our DRY leaves. More surprising, however, was the reduced consumption rates of Stenophylax when fed on an INT diet in comparison to the PERM diet, given the similarities between these types of leaves. Such differences in consumption despite similarities in leaf nutrient content and microbial biomass suggest that leaf palatability might also have been affected by other leaf characteristics that were not measured in this study such as leaf toughness or fungal diversity (Gonçalves et al. 2016). Because effects on microorganisms increase with drying duration (Langhans and Tockner 2006), changes in fungal activity or assemblage composition favouring more resistant or terrestrial species cannot be excluded. Several studies have shown that the consumption rates of shredders vary according to the fungal species in leaf assemblages (Arsuffi and
Physella
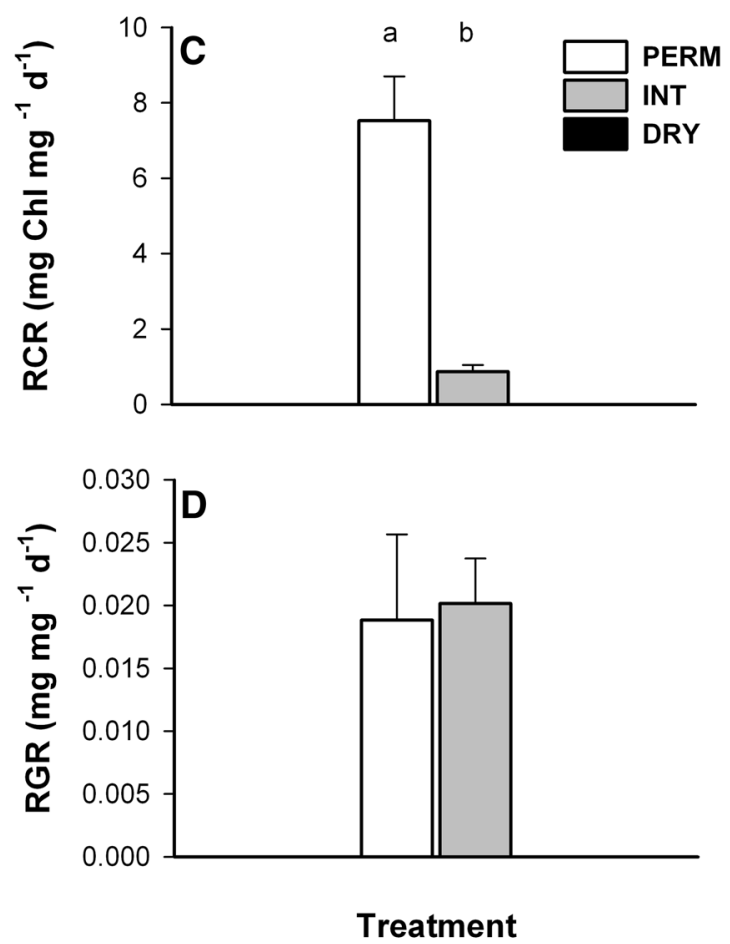

growth rate (RGR; b $n=10$ and $\mathbf{d} n=8-10)$. Values are means \pm SE. The experiment lasted 28 days for Stenophylax and 14 days for Physella. Different letters indicate significant differences (Tukey's HSD, $P<0.050)$

Suberkropp 1984; Chung and Suberkropp 2009; Jabiol and Chauvet 2012), whereas lower microbial activity during the terrestrial phase (Langhans et al. 2008; Larned et al. 2010; Bruder et al. 2011) might have prevented the degradation of repellent secondary metabolites or more recalcitrant $\mathrm{C}$, such as cellulose, lignin or condensed tannins, resulting in increased leaf toughness and thus, less palatable leaves in the INT than PERM treatments (Irons et al. 1988; Hladyz et al. 2009; Graça and Cressa 2010; Aßmann et al. 2011).

As expected, the increased consumption of PERM leaves translated into higher growth rates, which is consistent with the bigger size at eclosion found for an insect detritivore reared on continuously submerged resources (Aspbury and Juliano 1998). Although growth on a DRY leaf diet was reduced, it was not significantly lower than on the PERM diet. This result was unexpected given the lower ingestion rates and $\mathrm{N}$ concentration in leaves, which has been related to dampened growth rates in caddisflies (Iversen 1974; González et al. 2014; Frainer et al. 2016). Because leaves rapidly lose large quantities of fatty acids (including polyunsaturated and essential fatty acids) during decomposition in streams (Torres-Ruiz and Wehr 2010), more labile C, such as essential fatty acids and carbohydrates, might have 
been available to detritivores fed on DRY leaves, which could have mitigated any further effects on growth. Larvae fed on DRY leaves also had a higher \%P, which, consistent with the growth rate hypothesis, could be related to P-rich rRNA (Elser et al. 2003), and thus, contributed to high growth rates in this treatment. The decrease in $\% \mathrm{~N}$ in DRY detritivores' body tissue, probably in response to its lower concentration in leaves, might also have contributed to the relative increase in $\mathrm{P}$. Although changes in $\mathrm{N}$ were modest, their effects on case-building detritivores could be noteworthy (Stevens et al. 2000; Mckie 2004), as the allocation of protein (silk) to case building appears to be a fixed trait (Friberg and Jacobsen 1999), and can reduce larval protein by up to 35\% (Mondy et al. 2011). Therefore, despite the lack of short time effects on growth (but see Frainer et al. 2016), further effects on detritivore fitness cannot be excluded.

Similarly to Stenophylax, Physella consumption rates were drastically reduced when fed on INT biofilm, in contrast with the compensatory feeding on lower quality resources previously described for a herbivorous snail (Fink and Von Elert 2006). Stelzer and Lamberti (2002) found that ingestion rates increased with periphyton availability, irrespective of differences in their nutrient content. In our experiment, chlorophyll was lower in the INT treatment but the $\%$ of offered chlorophyll consumed was similar in both treatments (from 40 to $60 \%$ and 50 to $70 \%$ in the PERM and INT treatments, respectively), suggesting that the differences in chlorophyll consumption might be related to differences in resource quantity (i.e. biofilm thickness) rather than quality.

Although food quantity may have limited scraper consumption, biofilm availability did not constrain growth, as otherwise, negative or null growth would have been observed in the INT treatment. Herbivore growth is limited by high C:P ratios in the periphyton (Stelzer and Lamberti 2002; Frost and Elser 2002b; Ohta et al. 2011). As our biofilm C:P ratios in both treatments were either in the upper range or much higher than in previous studies, $\mathrm{P}$ might also have limited growth in our experiment. However, the increased consumption rates under the PERM treatment should have partly compensated for this deficit (passive feeding compensation sensu Stelzer and Lamberti (2002)], and thus, higher growth rates in PERM herbivores would have been expected. Whether this lack of response resulted from the shorter duration of our experiment (14 days for Physella; c.f. Stelzer and Lamberti (2002); Fink and Von Elert (2006); Ohta et al. (2011)] or due to herbivore behavioural or physiological adjustments, through selective feeding or increased assimilation efficiency for the limiting nutrient (Frost et al. 2005; Hessen et al. 2013), warrants further research. Nevertheless, Liess and Hillebrand (2005) showed that some herbivores can adjust their metabolism in response to changes in periphyton nutrient concentration during a 14-day experiment.

In conclusion, our results showed that stream drying lowered microbial colonization and nitrogen accrual in resources, which translated into lower shredder and herbivore consumption rates and detritivore growth. However, effects differed between allochthonous resources exposed to different drying regimes. Leaf packs before submergence maintained many nutritional and microbial characteristics of flow-conditioned leaves when exposed on the stream bank and recovered quickly after rewetting. In contrast, the autumnal ambient humidity proved insufficient to enhance microbial conditioning in terrestrially conditioned leaves (DRY; even after 2 months) or to maintain the quality of the more exposed epilithic biofilm. Drying also caused a decrease in the consumption and growth rates of shredders. Although Stenophylax is adapted to temporary streams (Tierno de Figueroa et al. 2013), our results indicate that upon rewetting, this caddisfly might show reduced growth rates due to impaired leaf quality when dryness conditions extend. Finally, if the observed effects extend to a wider number of species, bottom-up effects of stream drying through resource quality are likely to impact stream ecosystems by reducing both stream secondary production (Ledger et al. 2011) and invertebrate-mediated organic matter cycling under a drier climate scenario.

Acknowledgements This study was funded by the European Union's Seventh Programme through the GLOBAQUA project (Grant Agreement No. 603629) and FUNSTREAM Project (CGL201458760-C3-1-R) funded by the Spanish Ministry of Economy and Competitiveness. EMM held a doctoral fellowship (FI) from the Government of Catalonia.

\section{Compliance with ethical standards}

Conflict of interest The authors declare that they have no conflict of interest.

Open Access This article is distributed under the terms of the Creative Commons Attribution 4.0 International License (http:// creativecommons.org/licenses/by/4.0/), which permits unrestricted use, distribution, and reproduction in any medium, provided you give appropriate credit to the original author(s) and the source, provide a link to the Creative Commons license, and indicate if changes were made.

\section{References}

APHA (1989) Standard methods for the examination of water and wastewater 17th ed. American Public Health Association, Washington DC

Arnell NW (1999) The effect of climate change on hydrological regimes. Europe: a continental perspective. Glob Environ Change 9:5-23 
Arsuffi TL, Suberkropp K (1984) Leaf processing capabilities of aquatic Hyphomycetes: interspecific differences and influence on shredder feeding preferences. Oikos 42:144-154

Aspbury AS, Juliano SA (1998) Negative effects of habitat drying and prior exploitation on the detritus resource in an ephemeral aquatic habitat. Oecologia 115:137-148

Aßmann C, Rinke K, Nechwatal J, Von Elert E (2011) Consequences of the colonisation of leaves by fungi and oomycetes for leaf consumption by a gammarid shredder. Freshw Biol 56:839-852

Bernal S, Butturini A, Sabater F (2002) Variability of DOC and nitrate responses to storms in a small Mediterranean forested catchment. Hydrol Earth Syst Sci Discuss 6:1031-1041

Bligh EG, Dyer WJ (1959) A rapid method of total lipid extraction and purification. Can J Biochem Physiol 37:911-917

Bonada N, Resh VH (2013) Mediterranean-climate streams and rivers: geographically separated but ecologically comparable freshwater systems. Hydrobiologia 719:1-29

Bonada N., Zamora-Muñoz C., Rieradevall M., Prat N. (2004) Trichoptera (Insecta) collected in Mediterranean river basins of the Iberian peninsula: taxonomic remarks and notes on ecology. Graellsia 60:41-69

Boulton AJ (2003) Parallels and contrasts in the effects of drought on stream macroinvertebrate assemblages. Freshw Biol 48:1173-1185

Boulton AJ, Lake PS (1992) Benthic organic matter and detritivorous macroinvertebrates in two intermittent streams in south-eastern Australia. Hydrobiologia 241:107-118

Bruder A, Chauvet E, Gessner MO (2011) Litter diversity fungal decomposers and litter decomposition under simulated stream intermittency. Funct Ecol 25:1269-1277

Chung N, Suberkropp K (2009) Effects of aquatic fungi on feeding preferences and bioenergetics of Pycnopsyche gentilis (Trichoptera: Limnephilidae). Hydrobiologia 630:257-269

Cummins KW, Klug MJ (1979) Feeding ecology of stream invertebrates. Annu Rev Ecol Syst 10:147-172

Danger M, Cornut J, Elger A, Chauvet E (2012) Effects of burial on leaf litter quality microbial conditioning and palatability to three shredder taxa. Freshw Biol 57:1017-1030

Dewson ZS, Russell G (2007) Invertebrate community responses to experimentally reduced discharge in small streams of different water quality. J N Am Benthol Soc 26:754-766

Elser JJ, Acharya K, Kyle M, Cotner J, Makino W, Markow T, Watts T, Hobbie S, Fagan W, Schade J, Hood J, Sterner RW (2003) Growth rate-stoichiometry couplings in diverse biota. Ecol Lett 6:936-943

Fink P, Von Elert E (2006) Physiological responses to stoichiometric constraints: nutrient limitation and compensatory feeding in a freshwater snail. Oikos 115:484-494

Flores L, Larrañaga A, Elosegi A (2014) Compensatory feeding of a stream detritivore alleviates the effects of poor food quality when enough food is supplied. Freshw Sci 33:134-141

Frainer A, Jabiol J, Gessner MO, Bruder A, Chauvet E, McKie B-G (2016) Stoichiometric imbalances between detritus and detritivores are related to shifts in ecosystem functioning. Oikos $125: 861-871$

Friberg N, Jacobsen D (1999) Variation in growth of the detritivoreshredder Sericostoma personatum (Trichoptera). Freshw Biol 42:625-635

Frost PC, Elser JJ (2002) Growth responses of littoral mayflies to the phosphorus content of their food. Ecol Lett 5:232-240

Frost PC, Evans-White MA, Finkel ZV, Jensen TC, Matzek V (2005) Are you what you eat? Physiological constraints on organismal stoichiometry in an elementally imbalanced world. Oikos 109:18-25

Gessner MO (1991) Differences in processing dynamics of fresh and dried leaf litter in a stream ecosystem. Freshw Biol 26:387-398
Gessner M.O. (1997) Fungal biomass production and sporulation associated with particulate organic matter in streams. Limnetica 13:33-44

Gessner MO, Schmitt AL (1996) Use of solid-phase extraction to determine ergosterol concentrations in plant tissue colonized by fungi. Appl Environ Microbiol 62:415-419

Gonçalves AL, Lirio AV, Graça MAS, Canhoto C (2016) Fungal species diversity affects feaf decomposition after drought. Int Rev Hydrobiol 101:78-86

González AL, Romero GQ, Srivastava DS (2014) Detrital nutrient content determines growth rate and elemental composition of bromeliad-dwelling insects. Freshw Biol 59:737-747

Graça M.A.S. (2001) The role of invertebrates on leaf litter decomposition in streams-a review. Int Rev Hydrobiol 86:383-394

Graça M.A.S, Cressa C (2010) Leaf quality of some tropical and temperate tree species as food resource for stream shredders. Int Rev Hydrobiol 95:27-41

Graça M.A.S, Poquet JM (2014) Do climate and soil influence phenotypic variability in leaf litter microbial decomposition and shredder consumption? Oecologia 174:1021-1032

Graça MAS, Cressa C, Gessner MO, Feio MJ, Callies KA, Barrios C (2001) Food quality feeding preferences survival and growth of shredders from temperate and tropical streams. Freshw Biol 46:947-957

Headley JV, Peru KM, Verma B, Robarts RD (2002) Mass spectrometric determination of ergosterol in a prairie natural wetland. J Chromatogr A 958:149-156

Hessen DO, Elser JJ, Sterner RW, Urabe J (2013) Ecological stoichiometry: an elementary approach using basic principles. Limnol Oceanogr 58:2219-2236

Hladyz S, Gessner MO, Giller PS, Pozo J, Woodward G (2009) Resource quality and stoichiometric constraints on stream ecosystem functioning. Freshw Biol 54:957-970

IPCC (2013) Summary for policymakers. Climate change 2013: the physical science basis. Contribution of working group I to the fifth assessment report of the intergovernmental panel on climate change. Cambridge University Press Cambridge United Kingdom, New York NY USA

Irons JG, Oswood MW, Bryant JP (1988) Consumption of leaf detritus by a stream shredder: influence of tree species and nutrient status. Hydrobiologia 160:53-61

Iversen TM (1974) Ingestion and growth in Sericostoma personatum (Trichoptera) in relation to the nitrogen content of ingested leaves. Oikos 25:278-282

Jabiol J, Chauvet E (2012) Fungi are involved in the effects of litter mixtures on consumption by shredders. Freshw Biol 57:1667-1677

Jeffrey SW, Humphrey UG (1975) New spectrophotometric equations for determining chlorophyll $\mathrm{a} b$ and $\mathrm{c}$ in higher plants algae and phytoplankton. Biochemie und Physiologie der Pflanzen 191-194

Kendrick MR, Benstead JP (2013) Temperature and nutrient availability interact to mediate growth and body stoichiometry in a detritivorous stream insect. Freshw Biol 1820-1830

Koroleff F, Weinheimer F (1983) Simultaneous oxidation of nitrogen and phosphorus compounds by persulfate. In: Grasshoff K, Kremlingl K (eds) Methods of seawater analysis. 2nd edn. Verlag Chemie, Berlin Germany, p. 419

Langhans SD, Tockner K (2006) The role of timing duration and frequency of inundation in controlling leaf litter decomposition in a river-floodplain ecosystem (Tagliamento northeastern Italy). Oecologia 147:501-509

Langhans SD, Tiegs SD, Gessner MO, Tockner K (2008) Leafdecomposition heterogeneity across a riverine floodplain mosaic. Aquat Sci 70:337-346 
Larned ST, Datry T, Arscott DB, Tockner K (2010) Emerging concepts in temporary-river ecology. Freshw Biol 55:717-738

Ledger ME, Edwards FK, Brown LE, Milner AM, Woodward G (2011) Impact of simulated drought on ecosystem biomass production: an experimental test in stream mesocosms. Glob Change Biol 17:2288-2297

Liess A, Hillebrand H (2005) Stoichiometric variation in C:N C:P and $\mathrm{N}: \mathrm{P}$ ratios of littoral benthic invertebrates. J N Am Benthol Soc 24:256-269

Lytle D, Poff NL (2004) Adaptation to natural flow regimes. Trends Ecol Evol 19:94-100

Mas-Martí E, Romaní AM, Muñoz I (2015) Consequences of warming and resource quality on the stoichiometry and nutrient cycling of a stream shredder. PLoS ONE 10(3):e0118520. doi:10.1371/journal.pone.0118520

Mckie BG (2004) Disturbance and investment: developmental responses of tropical lotic midges to repeated tube destruction in the juvenile stages. Ecol Entomol 29:457-466

Molles MC Jr, Crawford CS, Ellis LM (1995) Effects of an experimental flood on litter dynamics in the middle Rio Grande riparian ecosystem. River Res Appl 11:275-281

Mondy N, Cathalan E, Hemmer C, Voituron Y (2011) The energetic costs of case construction in the caddisfly Limnephilus rhombicus: direct impacts on larvae and delayed impacts on adults. J Insect Physiol 57:197-202

Ohta T, Miyake Y, Hiura T (2011) Light intensity regulates growth and reproduction of a snail grazer (Gyraulus chinensis) through changes in the quality and biomass of stream periphyton. Freshw Biol 56:2260-2271

Pinheiro J, Bates D, DebRoy S, Sarkar D, R core Team (2017) nlme: Linear and Nonlinear Mixed Effects Models. R package version 3.1-129, https://CRAN.R-project.org/package=nlme.

Romaní AM, Amalfitano S, Artigas J, Fazi S, Sabater S, Timoner X, Ylla I, Zoppini A (2013) Microbial biofilm structure and organic matter use in mediterranean streams. Hydrobiologia 719:43-58

Sabater S, Artigas J, Gaudes A, Muñoz I, Urrea G, Romaní AM (2011) Long-term moderate nutrient inputs enhance autotrophy in a forested Mediterranean stream. Freshwater Biol $56: 1266-1280$
Sabater S, Tockner K (2010) Effects of hydrologic alterations on the ecological quality of river ecosystems. In: Sabater S, Barceló D (eds) Water scarcity in the Mediterranean. Springer, Berlin

Sanpera-Calbet I, Acuña V, Butturini A, Marcé R, Muñoz I (2016) El Niño southern oscillation and seasonal drought drive riparian input dynamics in a Mediterranean stream. Limnol Oceanogr 61:214-226

Stahl K, Hisdal H, Hannaford J, Tallaksen LM, van Lanen HaJ, Sauquet E, Demuth S, Fendekova M, Jódar J (2010) Streamflow trends in Europe: evidence from a dataset of near-natural catchments. Hydrol Earth Syst Sci 14:2367-2382

Stelzer RS, Lamberti GA (2002) Ecological stoichiometry in running waters: periphyton chemical composition and snail growth. Ecology 83:1039-1051

Sterner RW, Elser JJ (2002) Ecological stoichiometry. The biology of elements from molecules to the biosphere. Princeton University Press Princeton NJ

Stevens DJ, Hansell MH, Monaghan P (2000) Developmental tradeoffs and life histories: strategic allocation of resources in caddis flies. Proc R Soc 267:1511-1515

Tierno de Figueroa JM, López-Rodríguez MJ, Fenoglio S, SánchezCastillo P, Fochetti R (2013) Freshwater biodiversity in the rivers of the Mediterranean Basin. Hydrobiologia 719:137-186

Timoner X, Acuña V, Von Schiller D, Sabater S (2012) Functional responses of stream biofilms to flow cessation desiccation and rewetting. Freshw Biol 57:1565-1578

Torres-Ruiz M, Wehr JD (2010) Changes in the nutritional quality of decaying leaf litter in a stream based on fatty acid content. Hydrobiologia 651:265-278

Ylla I, Sanpera-Calbet I, Vázquez E, Romaní AM, Muñoz I, Butturini A, Sabater S (2010) Organic matter availability during pre- and post-drought periods in a Mediterranean stream. Hydrobiologia 657:217-232

Zöllner N., Kirsch K. (1962) Über die quantitative Bestimmung von Lipoiden (Mikromethode) mittels der vielen natülichen Lipoiden (allen bekanntem Plasmalipoiden) gemeinsamen Sulphophosphovanillin-Reaktion. Zeitsehrift ffir die gesamte experimentelle Medizin 135:545-561 